\begin{tabular}{|c|l|}
\hline Title & MDM2 regulates a novel form of incomplete neoplastic transformation of Theileria parva infected lymphocytes \\
\hline Author(s) & $\begin{array}{l}\text { Hayashida, Kyoko; Kajino, Kiichi; Hattori, Masakazu; W all lace, Maura; Morrison, Ivan; Greene, Mark I.; Sugimoto, } \\
\text { Chihiro }\end{array}$ \\
\hline Citation & $\begin{array}{l}\text { Experimental and Molecular Pathology, 94(1), 228-238 } \\
\text { https://doi.org/10.1016/.yexmp.2012.08.008 }\end{array}$ \\
\hline Issue Date & 2013.02 \\
\hline Doc URL & http:/hdl.handle.net/2115/52236 \\
\hline Type & article (author version) \\
\hline File Information & EMP941_228-238.pdf \\
\hline
\end{tabular}

Instructions for use 


\title{
MDM2 regulates a novel form of incomplete neoplastic transformation of Theileria parva infected
} lymphocytes

\section{Kyoko Hayashida $^{1}$, Kiichi Kajino ${ }^{1}$, Masakazu Hattori ${ }^{2}$, Maura Wallace ${ }^{3}$, Ivan Morrison ${ }^{4}$, Mark I. Greene ${ }^{5}$, and Chihiro Sugimoto ${ }^{1}$}

\section{${ }^{1}$ From the Division of Collaboration and Education, Hokkaido University}

Research Center for Zoonosis Control, Sapporo 001-0020, Japan

${ }^{2}$ Center for Innovation in Immunoregulative Technology and Therapeutics, Graduate School of Medicine, Kyoto University, Kyoto, Japan

${ }^{3}$ Department of Veterinary Clinical Studies, University of Edinburgh, Easter Bush Veterinary Centre, Roslin, Midlothian EH25 9RG, United Kingdom

${ }^{4}$ The Roslin Institute, Royal (Dick) School of Veterinary Studies, University of Edinburgh, Easter Bush, Roslin, Midlothian EH25 9RG, United Kingdom

${ }^{5}$ Department of Pathology and Laboratory Medicine, University of Pennsylvania, Philadelphia, PA 19104-6082, USA

Running title: MDM2 dependent transformation of T. parva infected lymphocyte

To whom correspondence should be addressed: Chihiro Sugimoto, Division of Collaboration and Education, Hokkaido University Research Center for Zoonosis Control, Sapporo 001-0020, Hokkaido, Japan. Tel.: (81) 11-706-5297; Fax: (81) 11-706-7370; E-mail: sugimoto@czc.hokudai.ac.jp

Keywords: Lymhoproliferation; Theileria parva; MDM2; p53

\begin{abstract}
Our efforts are concerned with identifying features of incomplete malignant transformation caused by non viral pathogens. Theileria parva (T. parva) is a tick-transmitted protozoan parasite that can cause a fatal lymphoproliferative disease in cattle. The T. parva-infected lymphocytes display a transformed phenotype and proliferate in culture media like the other tumor cells, however those cells will return to normal after antiprotozoal treatment reflecting the incomplete nature of transformation. To identify signaling pathways involved in this form of transformation of T. parva-infected cells, we screened a library of anticancer compounds. Among these, TIBC, a specific inhibitor of MDM2, markedly inhibited proliferation of $T$. parva-infected
\end{abstract}


lymphocytes and promoted apoptosis. Therefore we analyzed MDM2 function in T. parva-infected cells. Several T. parva-infected cell lines showed increased expression level of MDM2 with alternatively spliced isoforms compared to the lymphoma cells or ConA blasts. In addition, buparvaquone affected MDM2 expression in $T$. parva transformed cells. Moreover, p53 protein accumulation and function were impaired in T. parva-infected cells after cisplatin induced DNA damage despite the increased p53 transcription level. Finally, the treatment of T. parva-infected cells with boronic-chalcone derivatives TIBC restored p53 protein accumulation and induced Bax expression. These results suggest that the overexpression of MDM2 is closely linked to the inhibition of p53-dependent apoptosis of T. parva-infected lymphocytes. Aberrant expression of host lymphocyte MDM2 induced by cytoplasmic existence of T. parva, directly and/or indirectly, is associated with aspects of this type of transformation of T. parva-infected lymphocytes. This form of transformation shares features of oncogene induced malignant phenotype acquisition.

\section{Introduction}

Members of the genus Theileria are intracellular apicomplexan protozoan parasites transmitted by ticks. Among several Theileria species, T. parva is highly pathogenic for cattle and cause fatal lymphoproliferative diseases known as East Coast fever (Brown et al., 1973; Irvin et al., 1975; Lawrence and Irvin, 1994). The schizont stage of T. parva resides within leukocytes and has direct contact with the host-cell cytoplasm and matrix. T. parva is among several parasites that inhibit host-cell apoptosis pathways to ensure their intracellular survival (Heussler et al., 2001b). The parasites have the unique ability to transform host lymphocytes and to synchronize their division with that of the host cell (Hulliger et al., 1964; von Schubert et al., 2010), ensuring that infection is maintained in daughter lymphocytes. Parasite multiplication is dependent on host-cell proliferation. The transformation and immortalization of T. parva-infected cells is very reminiscent of tumor cells, a major difference being that T. parva-induced transformation is reversible, as leukocytes return to a resting phenotype upon elimination of the parasite by the anti-parasitic agent buparvaquone. This suggests that transformation is not dependent on defined genomic changes in the host cell (Dobbelaere and Heussler, 1999). However, the underlying mechanisms by which $T$. parva-induces incomplete transformation have not been defined.

p53 acts as a tumor suppressor in mammalian cells reviewed in (Gottlieb and Oren, 1996). Under normal conditions, p53 is maintained at low levels due to its rapid turnover and degradation by proteasomes (Vogelstein et al., 2000). In response to diverse types of stress, p53 can accumulate and can influence cell cycle progression. The mouse double minute $2(\mathrm{mdm} 2)$ gene was originally identified as an amplified gene on the double-minute chromosome in a spontaneously transformed mouse BALB/c 3T3 cell line (Cahilly-Snyder et al., 
1987). The MDM2 protein acts as a negative regulator of p53 through two known mechanisms: First, MDM2 binds p53 through its NH2-terminus, resulting in inhibition of its transcriptional activity (Momand et al., 1992), and second, the COOH-terminus of MDM2 serves as an E3 ubiquitin ligase targeting p53 for proteasomal degradation (Haupt et al., 1997). MDM2 can exhibit oncogenic activity when overexpressed in cells (Fakharzadeh et al., 1991), and gene amplification and overexpression of MDM2 protein are found in about 10\% of human tumors (Toledo and Wahl, 2006). In addition, many spliced isoforms of MDM2 are observed in human tumors, and the cDNA coding some of these spliced isoforms is also capable of transforming cells (Sigalas et al., 1996). Thus, both overexpression and alternative splicing of MDM2 are thought to contribute to its oncogenic function.

In this study, we screened T. parva-infected lymphocytes for susceptibility to a library of compounds with known anti mitotic activity in an attempt to identify signaling pathways involved in causing parasite-induced unlimited cell proliferation.

TIBC is an anticancer agent that has been suggested to affect the MDM2/p53 protein complex to selectively inhibit the growth of MDM2-overexpressing tumors (Kumar et al., 2003). The anti-tumor effects of TIBC, which have been confirmed in cancers in vitro and in vivo (Sasayama et al., 2007), has shown some promise for chemotherapeutic use, especially against tumors in which MDM2 overexpression occurs in the absence of genomic mutations in p53. In this study, we found that the TIBC specifically and efficiently inhibited proliferation of T. parva-infected lymphocytes, leading to apoptosis. We analyzed the MDM2 and p53 status of several T. parva-infected cell lines with respect to mRNA and/or protein expression levels to elucidate the fundamental mechanisms of incomplete transformation of lymphocyte induced by intracellular infection of $T$. parva.

\section{Materials and methods}

\section{Cell culture}

Cell lines infected with the Muguga or Marikebuni stocks of T. parva (Brown and Logan, 1986) were derived by in vitro infection of peripheral blood mononuclear cells (PBMC) or in one case (G6TpM, provided by Dr. R. Bishop, International Livestock Research Institute, Nairobi, Kenya) a cloned bovine T lymphoblastoid cell line, with sporozoites. Two of the lines (951-I38TPMa and 951-E43TPMa), derived from the same animal, had been cloned by limiting dilution and contained genotypically distinct parasite clones (Katzer et al., 2006). The designated numbers $(592,011,641$, or 951) indicate animal numbers of healthy Holstein cattle from which blood was collected. Control uninfected activated lymphocytes were prepared by stimulation of PBMCs from the same animals $(011,641$, and 951) with concanavalin A (ConA; $0.5 \mu \mathrm{g} / \mathrm{ml})$. T. parva-infected cell lines were maintained in RPMI-1640 culture medium containing 10\% heat-inactivated fetal bovine serum 
(FBS), $50 \mu \mathrm{M}$ 2-mercaptoethanol, 50 units $/ \mathrm{ml}$ penicillin, and $50 \mu \mathrm{g} / \mathrm{ml}$ streptomycin. For maintenance of ConA-treated lines, $10 \mathrm{U} / \mathrm{ml}$ recombinant mouse IL-2 (R\&D Systems) was also added to the medium. Madin Darbey bovine kidney (MDBK) cells and a bovine leukemia transformed cell line BTL-26 (kindly provided by Dr. N. Ishiguro, Gifu University, Japan) (Komori et al., 1996) were grown in Dulbecco's modified Eagle's medium supplemented with $10 \% \mathrm{FBS}, 50$ units $/ \mathrm{ml}$ penicillin, and $50 \mu \mathrm{g} / \mathrm{ml}$ streptomycin. To eliminate $T$. parva schizonts from the infected cells (011TPM), cells were cultured with $100 \mathrm{ng} / \mathrm{ml}$ buparvaquone (Butalex; Essex Animal Health) in the presence of $100 \mathrm{U} / \mathrm{ml}$ recombinant mouse IL-2 for 2 or 5 days. Studies involving the use of animals were conducted under a Project Licence issued by the UK Home Office and all experimental procedures were approved by the University of Edinburgh Animal Ethics Committee. The number of the Home Office Licence under which the work was carried out is 60/3736.

\section{Screening of compounds for inhibition of $T$. parva-infected cell proliferation}

Cell proliferation assays were performed to examine whether anticancer compounds affected growth of T. parva-infected lymphocytes. The SCADS inhibitor kits I and II, consisting of 190 kinds of inhibitors, were kindly provided by the Screening Committee of Anticancer Drugs supported by Grant-in-Aid for Scientific Research on Priority Area "Cancer" from The Ministry of Education, Culture, Sports, Science and Technology, Japan. These compounds were added to $5 \times 10^{4}$ T. parva-infected G6TpM cells or ConA-stimulated lymphocytes in 96-well plates at a concentration of $10 \mu \mathrm{M}$, then proliferation was quantified after $24 \mathrm{~h}$ incubation using a BrdU proliferation ELISA kit (Roche) according to the manufacturer's instructions.

\section{Effects of TIBC on cell death and p53 expression in T. parva-infected lymphocytes}

G6TpM cells $\left(1.5 \times 10^{5}\right)$, BTL-26 cells and MDBK cells were treated with TIBC (Merck-Calbiochem) for $50 \mathrm{~h}$ in 24 -well plates. For the detection of apoptotic cells, cells were stained with propidium iodide (PI) and Allophycocyanin-conjugated annexin V (BD Biosciences), and analyzed by flow cytometry on a FACSCanto cell analyzer (BD Biosciences). 011TPM, 951-E43TPMa, and 951ConA cells were similarly treated with TIBC in 24-well plates, and $2 \times 10^{4}$ cells from each treatment group were then transferred to a 96-well white plate. To indicate apoptosis, the activity of caspase 3 and 7 was quantified using the Caspase-Glo 3/7 kit (Promega) according to the manufacturer's instructions. Luminescence was measured with a luminometer (Victor; PerkinElmer). For the induction of DNA damage, 5×10 56 TpM, BTL-26, and MDBK cells were treated with cisplatin (Merck-Calbiochem) for $24 \mathrm{~h}$ at $0,5,20$ or $50 \mu \mathrm{M}$ in 8 -well plates, and subjected to Western blot analysis as described below. For detection of p53 protein or the transcript of its downstream target Bax, $5 \times 10^{5} \mathrm{G} 6 \mathrm{TpM}$ was treated with TIBC for $50 \mathrm{~h}$ at $0,5,10$ or $25 \mu \mathrm{M}$ in 8 -well plates. Cells were harvested, and Western blot analysis was performed as described below. 


\section{RT-PCR for detection of spliced isoforms of $\mathrm{mdm} 2$}

Total RNA was isolated from cells by the PureLink Micro-to-Midi Total RNA Purification System (Invitrogen). cDNAs were then synthesized from total RNA in the presence of oligo(dT) primers using a Ready-To-Go You-Prime First-Strand Beads kit (GE Healthcare) in accordance with the manufacturer's instructions. The resulting cDNAs were used in nested PCR to detect $m d m 2$. Nested PCR primers were designed based on the bovine $m d m 2$ sequence, mdm2F1 (5'-AACTGGGGAGCCTCGGGGGA-3') and mdm2R1 (5'-GGTATTATCTTGCTTTGATACACCT-3') for the first amplification, and mdm2F2 (5'-GTTAGTGAGCATCAGGCAAATGTG-3') and mdm2R2 (5-TTACAGGTAGTTCAACTAGGGG-3') for the second amplification. Each PCR was performed under the following conditions: $95^{\circ} \mathrm{C}$ for $1 \mathrm{~min}, 25$ amplification cycles $\left(95^{\circ} \mathrm{C}\right.$ for $1 \mathrm{~min}, 55^{\circ} \mathrm{C}$ for $1 \mathrm{~min}$, and $72^{\circ} \mathrm{C}$ for $\left.1 \mathrm{~min}\right)$, and a final extension step $\left(72^{\circ} \mathrm{C}\right.$ for 7 min). As an internal control, GAPDH amplification was performed with BoGAPDH-F (5'-TTCAACGGCACAGTCAAGG-3') and BoGAPDH-R (5'-ACATACTCAGCACCAGCATCAC-3'), using the conditions described above, except for the annealing temperature, which was $57^{\circ} \mathrm{C}$. Amplification of the $m d m 2 b$ isoform was also performed using specific primers (BoMBforward: 5'-AAGAGACCCTGGACTATTGGAAGTG-3' and

BoMBreverse: 5'-TGCCATTGAACCTTGTGTGATTTG-3') after a first amplification with mdm2F1 and mdm2R1, as previously described (Steinman et al., 2004). For $m d m 2 b$ isoform detection, a 30 amplification cycle was used while the rest of the PCR protocol remained the same as above. The PCR products were resolved on $1.2 \%$ agarose gels, isolated, cloned into the pGEM-T Easy Vector system (Promega), and sequenced in an ABI Prism 3700 Analyzer (Applied Biosystems).

\section{Quantitative RT-PCR}

The levels of transcription of $m d m 2$ and p53 were determined by quantitative RT-PCR with SYBR Premix Ex Taq (Takara) and Eva Green dye (Biotium). Values were normalized to the value of GAPDH. Primer sequences were as follows; MDM2: 5'-GGCATGCTTCACATGTGCAA-3' and 5'-GTACAATCATTTGAATTGGTTGCC-3'; p53: 5'-ACTGGAAGACTCTTGTGGTAACCT-3' and 5'-TTTTCTTCCTCAGTGCGGCGGTC-3'; GAPDH: 5'-GGTCATCATCTCTGCACCTTCTG-3' and 5'-AGGGTGTTGTTATACTTCTCGTGG-3'. Standard curves were constructed for all amplicons and each measurement was performed in triplicate. The reaction was performed at $95^{\circ} \mathrm{C}$ for $10 \mathrm{~s}$, followed by 40 amplification cycles $\left(95^{\circ} \mathrm{C}\right.$ for $10 \mathrm{~s}, 60^{\circ} \mathrm{C}$ for $\left.20 \mathrm{~s}\right)$ in a Mx3000P Real-Time PCR System (Stratagene).

\section{Western blot analysis}


Whole cell extracts were lysed in a lysis buffer (0.5\% TritonX-100, $50 \mathrm{mM}$ Tris- $\mathrm{HCl}$ [pH7.4], 150 $\mathrm{mM} \mathrm{NaCl}$ ) supplemented with a protease inhibitor cocktail (Complete Mini; Boehringer Mannheim) at $4^{\circ} \mathrm{C}$ for $10 \mathrm{~min}$, and centrifuged. Supernatants were resuspended in a sample buffer for sodium dodecyl sulfate polyacrylamide gel electrophoresis (SDS-PAGE) and heated at $100^{\circ} \mathrm{C}$ for $3 \mathrm{~min}$. The concentrations of the proteins were estimated using the BCA Protein Assay Reagent (Thermo Scientific) or Quant-iT Protein Assay kit (Invitrogen). Proteins from each sample $(30 \mu \mathrm{g})$ were subjected to electrophoresis in a polyacrylamide gel, and separated proteins were transferred to a sheet of PVDF membrane (Bio-Rad Laboratories). The filters were blocked in 5\% skim milk powder in Tris-buffered saline with $0.1 \%$ Tween 20 (TBS-T) for $1 \mathrm{~h}$ at room temperature, and washed with TBS-T three times for $10 \mathrm{~min}$ each. The filters were incubated with primary antibodies overnight at $4^{\circ} \mathrm{C}$, washed, and incubated for $1 \mathrm{~h}$ at room temperature with horseradish peroxidase-conjugated goat anti-mouse antibody (Zymed laboratories, cat. no. 62-6420; 1:3,000) or goat anti-rabbit antibody (Jackson ImmunoResearch, cat. no. 111-036-045; 1:6,000). The bands were visualized with SuperSignal West Femto Maximum sensitivity substrate (Thermo Scientific). Membranes were reprobed with another antibody after they were stripped with Restore Western Blot Stripping Buffer (Thermo Scientific). Antibodies used in this study were anti-MDM2 (N20; 1:1,000; Santa Cruz), anti-p53 (PAb421; 1:1,000; Merck-Calbiochem), anti-Bax (Poly6251; 1:3,000; BioLegend), and anti- $\beta$-actin (C4;1:3,000; Santa Cruz Biotechnology).

\section{Immunostaining}

For staining of MDM2, cytospin smears of T. parva-infected cells (G6TpM) were fixed with $4 \%$ paraformaldehyde/PBS at room temperature for $15 \mathrm{~min}$, permeabilized with $0.2 \%$ Triton $\mathrm{X}-100$ for 10 min and blocked with 5\% skimmed milk for $1 \mathrm{~h}$, before staining with anti-MDM2 (N20 diluted 1:500) for $1 \mathrm{~h}$ at room temperature followed by Alexa 594-conjugated anti-rabbit Ig (Invitrogen). Immunostaining for p53 was performed essentially as described by Haller et. al. (Haller et al., 2010). The slides were fixed with $3 \%$ paraformaldehyde/PBS for 10 min, permeabilized with $0.25 \%$ Triton X-100 for 10 min, blocked with $10 \%$ bovine serum albumin in PBS for 30 min, stained with anti-p53 (OP33, Calbiochem; 1:2000) overnight at $4^{\circ} \mathrm{C}$, and detected with Alexa 555-conjugated anti-mouse Ig (Invitrogen). DAPI (blue) was used for nuclear staining.

\section{Reporter assay}

To determine p53 activity in the cells, $5 \times 10^{5}$ T. parva-infected cells (G6TpM) and BTL-26 cells in 24-well plates were co-transfected with 500 ng of a p21 luciferase reporter plasmid (Shimizu et al., 2002) and a control plasmid containing Renilla luciferase pGL4.70 (25 ng; Promega). After $12 \mathrm{~h}$, cisplatin or TIBC was added to the culture, and cells were incubated for an additional $24 \mathrm{~h}$. Transfection was performed with the Neon 
Transfection System (Invitrogen) at $1300 \mathrm{~V}, 30 \mathrm{~ms}$ pulse width and one-time pulse. These conditions were optimized to achieve high levels of efficiency and viability (data not shown). Both firefly and Renilla luciferase activity was assayed with the Dual-Luciferase Reporter Assay System (Promega) and measured with a GloMax luminometer (Promega). The firefly signal was normalized using the Renilla luminescence signal.

\section{Results}

\section{Identification of signaling pathway related to proliferation of $T$. parva-infected lymphocytes}

We examined the effects of various chemical inhibitors using the SCADS inhibitor kits I and II, which consist of 190 inhibitors. In the first screening, 65 compounds were found to inhibit proliferation of $T$. parva (G6TpM)-infected cells by >90\% compared with cells mock-treated with DMSO. To exclude compounds with nonspecific cytotoxic activity, we carried out a second screening of these 65 compounds comparing their effect on T. parva (G6TpM)-infected and ConA-stimulated lymphocytes. Thirty-six compounds, targeting different signaling pathways, have shown to have specific effects on proliferation of T. parva-infected lymphocytes when compared with ConA-stimulated lymphocytes as listed in Table 1.

\section{The MDM2 inhibitor TIBC specifically induce apoptosis in T. parva-infected lymphocytes}

MDM2 is well-recognized oncoprotein that participates in the induction of malignant lymphoma when overexpressed in mice (Jones et al., 1998). MDM2 has not previously been studied in T. parva infection. The ability of the MDM2 inhibitor TIBC to induce apoptosis of T. parva-infected lymphocytes was examined. The T. parva-infected and non-infected cell lines used in this study are summarized in Table 2. T. parva-infected G6TpM cells displayed susceptibility to TIBC at high concentrations, exhibiting high levels of apoptosis, whereas the bovine leukemia cell line BTL-26 and MDBK cell line remained unaffected (Fig. 1A). The effects of TIBC on other T. parva-infected cells, including a different stock of T. parva (Marikebuni stock) and uninfected bovine lymphocytic cells (listed in Table 2) were further investigated. As shown in Fig. 1B, T. parva-infected cell lines (011TPM and 951-E43TPMa) were highly susceptible for TIBC induced apoptosis. Discernible pathologic effects were not observed in non-infected cells (951ConA) at the concentration used in the experiment. These results suggest that MDM2 participates in maintaining the immortalization of $T$. parva-infected lymphocytes.

\section{Isolation of spliced $m d m 2$ isoforms from $T$. parva-infected lymphocytes}

The complete coding region of bovine $m d m 2$ was isolated from a cDNA obtained from $T$. parva-infected G6TpM cells by nested RT-PCR (Fig. 2A). The bovine MDM2 amino acid sequence predicted 
from the resultant cDNA sequence showed 94\% amino acid identity with human MDM2 (HDM2; GenBank accession number NM_002392; Fig. 3A). Analysis of the $m d m 2$ PCR products from T. parva-infected lymphocytes revealed several shorter products in addition to an increased amount of the product corresponding to the full-length transcript (Full-mdm2), whereas no such changes to the amplification were observed in ConA cell lines 641 and 951, BTL-26 and MDBK cells (Fig. 2A). Cloning and sequencing of these RT-PCR products from T. parva-infected G6TpM cells led to identification of 4 alternatively spliced isoforms of $m d m 2$ transcripts from T. parva-infected lymphocytes, which were designated mdm2-TPalpha (GU951438), mdm2-TPFL7 (GU323559), $m d m 2-R 3 U$ (GU323560), and $m d m 2-T P R 3 L$ (GU323561). Two of these corresponded to transcripts described previously in other species (Fig. 3A): Mdm2-TPalpha contained an insert of 87 bp between exon 4 and 5, and this additional sequence contained a stop codon in-frame. This transcript corresponds to $m d m 2 \alpha$ identified from PBMC in human and dog (Veldhoen et al., 1999) and to $m d m 2-D S 3$ obtained from a soft tissue sarcoma (Bartel et al., 2001). This alpha domain sequence and the insertion sites found to be highly conserved between the human, canine, and bovine products (Fig. 3A). The mdm2-TPalpha sequence is predicted to disrupt the p53 binding domain of the MDM2 protein. The second splice variant, $m d m 2-T P F L 7$, in which exon 5 was aberrantly spliced to exon 12 , corresponds to $m d m 2-F B 28$ identified in pediatric rhabdomyosarcoma (Bartel et al., 2001). In the two novel alternatively spliced transcripts of MDM2, mdm2-TPR3U and $m d m 2-T P R 3 L$, exon 4 was aberrantly spliced to exon 12 . Mdm2-TPFL7 and $m d m 2-T P R 3 L$ caused a frame shift in the region encoding the C-terminus, resulting in completely new predicted amino acid sequences and loss of the RING domains, whereas $m d m 2-T P R 3 U$ and $m d m 2-T P a l p h a$ retain these domains. Because $m d m 2 b$ (HSU33200) is the most commonly found spliced isoform of $m d m 2$ in numerous types of cancer cells (Bartel et al., 2002), and it can induce cell transformation independently of p53 (Steinman et al., 2004), we examined transcription of bovine $m d m 2 b$ by nested RT-PCR using $m d m 2 b$-specific primers, as described previously (Steinman et al., 2004). The $m d m 2 b$ transcript is aberrantly spliced from exon 3 to exon 12 . $m d m 2 b$ transcripts were detected in T. parva-infected cell lines tested, but only a faint band were detected in uninfected ConA-stimulated lymphocytes (Fig. 2B), suggesting that an elevation of $m d m 2 b$ mRNA levels is associated with T. parva infection.

\section{MDM2 is overexpressed in cells infected with T. parva}

MDM2 is overexpressed in various tumors, and TIBC and nutlin-3 are effective at inhibiting the growth of MDM2-overexpressing cells, such as breast cancer cells (Kumar et al., 2003), glioma cells (Sasayama et al., 2007), and human pediatric acute lymphoblastic leukemia cells (Gu et al., 2008). The finding that $T$. parva-infected lymphocytes are sensitive to MDM2 inhibitors led us to investigate protein expression levels of MDM2. We performed Western blot analysis with anti-MDM2 antibody (N20) and found that T. parva-infected 
cells had increased MDM2 levels, compared to ConA-stimulated lymphocytes (Fig. 4A). As observed for sensitivity to TIBC, the expression levels of MDM2 varied depending on the parasitized cell line examined. The highest expression level of MDM2 was observed in the 592TPM cell line (T. parva -infected B cell line). Since Theileria infection does not always result in the same patterns of host cell signaling pathway activation in cell lines of different phenotype (Guergnon et al., 2003; Rocchi et al., 2006), this variation in expression levels of MDM2 may be due to difference in host cell phenotype and/or the parasite species or strain. Elimination of the parasite by treatment with the theilericidal drug buparvaquone led to the disappearance of the MDM2 bands (Fig. 4B). No obviously elevated levels of MDM2 expressions were observed in BTL-26 or MDBK cells (Fig. 4C). Because the T. parva-infected cell lines express several alternative transcription variants, next we evaluated transcript abundance of $m d m 2$ mRNA including transcription isoforms by quantitative RT-PCR, and the expression levels were normalized against glyceraldehyde-3-phosphate dehydrogenase (GAPDH). The primer pair for $m d m 2$ quantitative RT-PCR is able to detect not only full-length $m d m 2$ but also other three p53 binding domain defective transcription variants, $m d m 2-T P \alpha, m d m 2-T P R 3 U$ and $m d m 2-T P b$. The transcription levels of all T. parva-infected cells were more than three times higher than those of any ConA blast or BTL-26 cells (Fig. 4D and E). Various forms of MDM2 are over expressed in T. parva-infected cells.

\section{p53 accumulation in response to DNA damage is disordered in T. parva-infected lymphocytes}

Cisplatin binds to DNA and forms platinum-DNA adducts, resulting in p53 accumulation and induction of apoptosis (Siddik, 2003). To examine p53 protein activity in T. parva-infected lymphocytes, expression in T. parva-infected and uninfected cell lines prior to and/or after (24h) treatment with cisplatin was compared by Western blot analysis. In both uninfected cell lines (BTL-26, MDBK cells), the levels of p53 increased after treatment with cisplatin, whereas the T. parva-infected cells (G6TpM) showed no apparent accumulation of p53 protein following cisplatin-treatment (Fig. 5A). The transcription levels of p53 were also determined by quantitative RT-PCR in T. parva-infected cells (G6TpM), BTL-26 cells, and MDBK cells after treatment with cisplatin. Transcription of p53 was further upregulated in the T. parva-infected cells by the cisplatin treatment, but was unaffected in the two uninfected cell lines (Fig. 5B). In addition, p21-luciferase reporter assay indicated that p53 activities after cisplatin treatment in $T$. parva-infected cells remained unaffected despite those in control BTL-26 cells increased in dose dependent manner (Fig. 5C), consistent with the results of Western blot analysis in Fig. 5a. These observations indicate that p53 protein accumulation and activity is impaired in T. parva-infected lymphocytes.

\section{TIBC restores the 533 response in $T$. parva-infected lymphocytes}

To determine whether impairment of p53 accumulation was associated with MDM2 overexpression, 
we examined the status of p53 after treatment with TIBC. Western blot analysis showed an increased level of p53 protein after $24 \mathrm{~h}$ of exposure to TIBC in T. parva-infected cells (G6TpM). Expression of the pro-apoptotic molecule Bax, a p53 target, was also elevated in G6TpM cells (Fig. 5D), indicating that the p53 pathway remained functional in T. parva-infected lymphocytes and could be restored by inhibiting MDM2 activity. Consistent with the restoration of p53 protein, increased p53 activity in TIBC-treated T. parva-infected G6TpM cells was also confirmed using a p21-reporter plasmid assay as shown in Fig. 5C.

\section{Nuclear accumulation of $\mathrm{p53}$ were induced by TIBC treatment}

Activation of p53 is accompanied by its stabilization and nuclear accumulation by MDM2. To determine cellular the distribution of p53 after abrogation of MDM2 function, T. parva-infected cells were stained with anti-p53 before and after treatment of TIBC for $48 \mathrm{~h}$. While untreated cells showed undetectable levels of p53 protein, TIBC treatment for $48 \mathrm{~h}$ lead to the accumulation of p53 in nucleus, most likely in the nucleoli (Fig. 6A). On the other hand, MDM2 were distributed mainly in the nucleoplasm (Fig. 6B upper). Disappearance of MDM2 staining signals in the cells which showed typical apoptotic morphological changes of nucleus (arrowhead) after induction of apoptosis by theilericidal drug buparvaquone were observed, indicating that the expression of MDM2 is regulated by the presence of the parasite.

\section{Discussion}

Transformation features of T. parva-infected lymphocytes are sensitive to the MDM2 inhibitor TIBC. Infected cells express high levels of MDM2 and have several alternatively spliced $m d m 2$ transcripts. The overexpression of MDM2 protein in T. parva-infected cells was associated with enhanced transcription or increased stability of $m d m 2$ mRNA as demonstrated by real-time RT-PCR. MDM2 is an oncoprotein that controls tumorigenesis through both p53-dependent and p53-independent mechanisms (Bartel et al., 2002). It is known that the p53-dependent mechanism involves inhibition of p53 activity by MDM2, by direct-binding (Momand et al., 1992), shuttling p53 from the nucleus to the cytoplasm (Tao and Levine, 1999), and inducing ubiquitination and hence degradation by the ubiquitin-proteasome system (Haupt et al., 1997). Several lines of evidence support a role for p53-independent functions of MDM2 in tumor formation (Bouska et al., 2008; Ganguli and Wasylyk, 2003).

p53 is a major regulator of cell homeostasis in response to insults such as radiation damage, microbial infection, or tumorigenesis (del Aguila et al., 2006; Teodoro and Branton, 1997; Vousden and Lu, 2002). Oncogenes that deliver strong mitogenic signals cause cellular senescence that arrests cell proliferation or causes apoptosis by the p53-dependent pathway (Yaswen and Campisi, 2007). Because Theileria infection results in strong mitogenic stimulation and the majority of infected cells retain wild-type p53, activation of p53 
might be expected to retard proliferation and allow elimination of the infected cells. However, T. parva-infected cells acquire the ability to proliferate indefinitely, avoiding cell-cycle arrest and apoptosis. Indeed, a recent study by Haller et al. (2010) demonstrated that p53-mediated host cell apoptosis is suppressed during Theileria infection, but is rapidly re-activated after elimination of the parasite by the anti-parasitic drug treatment (Haller et al., 2010). Notably, we detected an mRNA in T. parva-infected lymphocytes predicted to encoding a protein homologous to $m d m 2 b$, which has been reported to have p53-independent tumorigenicity (Steinman et al., 2004). Among 5 spliced isoforms of $m d m 2$ detected in $T$. parva-infected lymphocytes, three of them corresponded to previously reported spliced isoform sequences of $m d m 2$ ( $m d m 2-T P 2 \mathrm{~b}$ corresponded to human $m d m 2 b$, $m d m 2-T P \alpha$ corresponded to human $m d m 2 \alpha$, and $m d m 2-T P F L 7$ corresponded to $m d m 2-F B 28$ from human rhabdomyosarcoma), whereas the other two isoforms ( $m d m 2-T P R 3 U$ and $m d m 2-T P R 3 L)$ were novel. The predicted protein products of all of them lacked the p53-binding domain, but $m d m 2-T P \alpha, m d m 2-T P R 3 U$, and $m d m 2-T P 2 b$ still bore the RING finger domain at the C-terminus. The C-terminal RING finger domain of MDM2 contains a cysteine residue that is essential for its function as an E3 ubiquitin conjugating enzyme and for its ability to induce degradation of p53 (Honda and Yasuda, 2000). We did not determine whether these spliced isoforms of mdm2 were expressed as protein species, but we speculate that one or more of the isoforms play some role of incomplete transformation of $T$. parva-infected cells by p53-independent mechanisms. Alternatively, expression of spliced isoforms of $m d m 2$ may merely be a secondary phenomenon associated with excess transcription of $m d m 2$, because spliced forms of $m d m 2$ mRNA were usually found together with full-length MDM2 transcripts (Bartel et al., 2002).

Upon DNA damage, p53-MDM2 interactions are affected by phosphorylation of p53 (Bode and Dong, 2004). Indeed, in our study, p53 protein was increased after cisplatin treatment in control cells (BTL-26 or MDBK) without an increase in p53 mRNA transcription, suggesting that p53 levels in these cells were post-transcriptionaly controlled by MDM2 preventing the degradation of p53. In contrast, $T$. parva-infected lymphocytes were not responsive to cisplatin-induced p53 accumulation. We noted that p53 mRNA was upregulated, suggesting that the absence of p53 accumulation is post-transcriptionally controlled, either by translation failure or excessive degradation, rather than the result of a reduced transcription rate. Since MDM2 was aberrantly overexpressed in T. parva-infected cells, active degradation of p53 may be the most likely explanation for the defective p53 response. The enhanced transcription of $p 53$ may be caused by MDM2, which induces p53 translation as a negative feedback loop (Wu X Fau - Bayle et al., 1993). To test the hypothesis that the p53 dysfunction was caused by aberrant MDM2 expression, we examined the status of p53 after treatment with a MDM2 inhibitor. Indeed, the MDM2 inhibitor TIBC rescued normal p53 accumulation with transcriptional function, and caused apoptosis of the $T$. parva-infected lymphocytes, suggesting that over-expression of MDM2 contributed to the perturbation of the p53 pathway. 
In our studies, p53 was mainly localized within the nucleus of the infected cells, and the staining signal for p53 in the nucleus was increased after TIBC treatment (Fig. 6A). Other workers have reported that p53 in T. parva-infected cells is associated with the schizont membrane (Haller et al., 2010) but how the parasite sequesters p53 to this location was not determined. The reason for the apparent discrepancy between our p53 staining pattern and that obtained by Haller $e t a l$. is unclear. Haller $e t$ al. proposed sequestration to the parasite surface as a mechanism for p53-suppression in Theileria-infected cells. However, it is uncertain whether all synthesized p53 molecules could be recruited to the parasite surface. It is possible that only p53 protein that evades the p53-degradation process is trapped to the parasite membrane. Considering the consistent expression of intact forms of $\mathrm{p} 53$, degradation of $\mathrm{p} 53$ by MDM2, in addition to cytoplasmic sequestration, may be required for host cell survival and continued proliferation of the parasite. The findings, from these two studies indicate that Theileria might negatively regulate p53 by two means, one by sequestration and another by active degradation of it.

In T. parva-infected cells, MDM2 was primarily localized to the host nucleoplasm (Fig. 6B). In untransformed cells, $\mathrm{p} 14^{\mathrm{ARF}}-/ \mathrm{p} 19^{\mathrm{ARF}}$ negatively regulates MDM2 by sequestering MDM2 from the nucleoplasm to nucleoli, which results in the accumulation of p53 in the nucleoplasm (Weber et al., 1999). The observed nucleoplasmic localization of MDM2 in the T. parva-infected cells might be linked indirectly to altered ARF function by the infection.

. The molecules known to regulate the transcription of $m d m 2$ include p53 (Juven et al., 1993), AP-1, Ets (Phelps et al., 2003), and PTEN (Chang et al., 2004). The nuclear factor-kappa B (NF-kB) is also a transcription regulator of MDM2 through its binding to the P1 promoter, and has been shown to induce MDM2 expression in mouse embryonic fibroblasts (Tergaonkar et al., 2002) and activated T cells (Busuttil et al., 2010).

Inhibition of the multi-subunit I kappa B kinase suppresses MDM2 expression levels in Epstein Barr virus-infected cells, suggesting that the steady-state protein level of MDM2 can be controlled by NF-kB activity (Forte and Luftig, 2009). NF-kB is constitutively activated in T. parva-infected lymphocytes as a consequence of modulation of multi-subunit IкB kinase signalosome complex (Heussler et al., 1999; Heussler et al., 2002; Ivanov et al., 1989). Hence, NF-кB activation may be a key step for constitutive upregulation of MDM2 in $T$. parva-infected lymphocytes.

In addition to NF-kB activation, the phosphoinositide 3-kinase (PI3-K)/Akt pathway may be relevant to functional activation of MDM2. Phosphorylation of MDM2 by Akt/PKB has been reported to result in nuclear translocation of MDM2 (Mayo and Donner, 2001), enhancement of MDM2-mediated ubiquitination of p53 (Ogawara et al., 2002), and stabilization of MDM2 by preventing self-ubiquitination (Feng et al., 2004). Intriguingly, the PI3-K/Akt pathway is also known to be constitutively activated in T. parva-infected cells (Heussler et al., 2001a). Thus, constitutive activation of both the NF-KB and the PI3-K/Akt pathway could favor 
survival of parasitized cells by promoting MDM2 expression and enhancing its function, as well as stimulating the expression of anti-apoptotic and pro-proliferative genes (Dobbelaere et al., 2000; Dobbelaere and Kuenzi, 2004; Shiels et al., 2006).

Our results indicate that enhanced expression of MDM2 in T. parva-infected cells alters p53 stabilization. These results document a mechanism by which incomplete transformation of cells occurs as a consequence of pathogenic infection by protozoa.

\section{Acknowledgments}

We thank Dr. R. Bishop for providing the T. parva (Muguga stock)-infected G6TpM cell line. We also thank Dr. N. Ishiguro for providing BTL-26 cell line. This work was supported in part by the Grants-in-Aid for Scientific Research and Asia-Africa S \& T Strategic Cooperation Promotion Program by the Special Coordination Funds for Promoting Science \& Technology, from the Ministry of Education, Culture, Sports, Science and Technology of Japan (MEXT) to CS. KH was supported by the Program of Founding Research Centers for Emerging and Reemerging Infectious Diseases, MEXT.

\section{Figure Legends}

Fig. 1 Apoptotic effects of the MDM2 inhibitor TIBC on T. parva-infected lymphocytes. (A) $T$. parva-infected lymphocytes (G6TpM), BTL-26 cells, and MDBK cells were treated with TIBC for $50 \mathrm{~h}$ at the indicated concentrations. After $50 \mathrm{~h}$, the percentage of apoptotic cells was determined by flow cytometry after annexin V staining. Annexin V-positive cells were considered to be apoptotic (including cells in early apoptosis and late apoptosis/necrosis). Experiments were repeated three times, and the mean results of three experiments are shown. Error bars represent SD (n = 3). (B) 011TPM, 951-E43TMA, and 951ConA cells were treated with

TIBC for $48 \mathrm{~h}$. After $48 \mathrm{~h}$ treatment, the degree of apoptosis was determined by measuring the activity of caspase 3 and 7, which is shown as the fold increase over cells mock-treated with DMSO. A representative result of three independent experiments is shown.

Fig. 2 Identification of alternatively spliced isoforms of $m d m 2$ in $T$. parva-infected lymphocytes. (A) Semiquantitative RT-PCR analysis of $m d m 2$ expression in T. parva-infected lymphocytes or uninfected cells. Expression of mRNA for $m d m 2$ and gapdh was evaluated by RT-PCR. The position of the full-length $m d m 2$ transcript (1513 bp) is indicated by an arrow. Several shorter products considered to be spliced isoforms of $m d m 2$ are shown with a bracket. (B) $M d m 2 b$ was detected in $T$. parva-infected lymphocytes by a set of primers specific for bovine $m d m 2 b$. Expression of $m d m 2 b$ mRNA, which is one of the spliced isoforms of $m d m 2$, was evaluated by nested RT-PCR using $m d m 2 b$-specific primers. GAPDH amplification was performed as an internal 
control.

Fig. 3 Comparison of the nucleotide sequences of spliced $\boldsymbol{m d} \boldsymbol{m} \mathbf{2}$ isoforms. (A) Alignment of MDM2 amino acid sequences identified in T. parva-infected lymphocytes and related genes. GenBank accession numbers or references for the genes are MDM2-TPalpha (GU951438), MDM2-TPR3U (GU323560), MDM2-TPR3L (GU323561), MDM2-TPFL7 (GU323559), FB28 (AF385324), human MDM2b (NM_006879), and canine alpha domain. The arrow indicates positions of bovine $m d m 2 b$-specific forward primer. (B) Schematic representation of the full-length transcript and spliced isoforms of $m d m 2$ isolated from $T$. parva-infected lymphocytes. The arrow shows the transcription start site, and the indicated exon numbers correspond to those in human/mouse $m d m 2$. Dotted lines indicate splicing connections.

Fig. 4 MDM2 is overexpressed in T. parva-infected lymphocytes. (A) Western blot analysis of MDM2 using an antibody specific for MDM2 (N20 from Santa Cruz). The N20 antibody was raised against an N-terminal fragment of human MDM2 and can recognize most spliced isoforms of MDM2 because the N-terminus is retained in the splice variants. NS = nonspecific. Arrows indicate 90-kDa forms of MDM2. (B) Expression of MDM2 after parasite elimination. To eliminate he parasite from the cell, the theilericidal drug buparvaquone $(100 \mathrm{ng} / \mathrm{ml})$ was added to TPM011 cells for 2 or 5 days in the presence of $10 \mathrm{U} / \mathrm{ml} \mathrm{IL}-2$. Cell lysates were subjected to Western blot analysis for MDM2 and $\beta$-actin as a loading control. (C) Expression of MDM2 in T. parva-infected or non-infected cells. G6TpM, BTL-26, and MDBK cells were analyzed by Western blot analysis for their expression levels of MDM2 and beta-actin as a loading control. (D) Transcripts of $m d m 2$ from $T$. parva-infected or ConA-stimulated lymphocytes were quantified using real-time RT-PCR and normalized to GAPDH. Transcription levels of $m d m 2$ in these cells are expressed as ratios to the level obtained following stimulation of PBMCs from animal 011 with ConA (ConA-011), which was set to 1.0. Experiments were repeated three times, and a representative experiment in triplicate is shown. Bars represent the mean $\pm \operatorname{SE}(n=$ 3). (E) Real-time PCR for $m d m 2$ transcripts in G6TpM, BTL-26, and MDBK cells. The obtained values for $m d m 2$ were normalized to GAPDH and are shown as ratios of the value obtained in BTL-26 cells. The mean result of the triplicate is shown. Experiments were repeated three times, and representative experiment is shown. Bars represent the mean $\pm \mathrm{SE}(\mathrm{n}=3)$.

Fig. 5 Impairment of p53 accumulation after DNA damage in $\boldsymbol{T}$. parva-infected lymphocytes. (A) The status of p53 expression following treatment of cells with cisplatin. T. parva-infected lymphocytes (G6TpM), BTL-26 cells, and MDBK cells were treated with cisplatin for $24 \mathrm{~h}$ and harvested. Cell lysates were subjected to Western blot analysis using monoclonal antibodies specific for p53 and $\beta$-actin (as a loading control). (B) Quantification 
of p53 mRNA expression in T. parva-infected G6TpM cells following cisplatin treatment. p53 mRNA was quantified by real-time RT-PCR and normalized against GAPDH. The level of transcription obtained with ConA-011 was set to 1, and expression levels in other samples are expressed as ratios relative to that in ConA-011 cells. Bars represent the mean \pm SE $(n=3)$. (C) Reporter plasmid p21-luciferase together with the control reporter plasmid pGL4.70 was co-transfected into T. parva-infected cells (G6TpM) and BTL-26 cells. Cells were incubated with cisplatin or TIBC for $24 \mathrm{~h}$ at the indicated concentration $12 \mathrm{~h}$ after transfection. Firefly luciferase driven by the p 21 promoter was normalized to the control Renilla luciferase activity. The p53 activity in non-treated cells was set to 1 , and activity in other cells is expressed as a ratio of this value. Data are representative of three independent experiments. (D) p53 accumulation in T. parva-infected cells caused by MDM2 inhibitor TIBC treatment, and subsequent Bax expression. T. parva-infected lymphocytes (G6TpM) were treated with the MDM2 inhibitor TIBC for $24 \mathrm{~h}$ at the indicated concentrations and harvested. Western blot analysis was performed on cell lysates using antibodies specific for p53, Bax, and $\beta$-actin (as a loading control).

Fig.6 Localization of MDM2 and p53 in T. parva-infected cells.

(A) T. parva-infected cells (G6TpM) were stained with anti-p53 (Red). The weak signals were observed in host nucleus but not in parasite surface (Upper; TIBC 0h). After TIBC treatment for $48 \mathrm{~h}$ (Lower; TIBC 48h), the p53 signals (Red) were more detectable at the host nucleus than non-treated cells. (B) T. parva-infected cells (G6TpM) were stained with anti-MDM2 (Red). MDM2 was mainly localized to the host nucleoplasm. Host and parasite DNA were stained with DAPI (blue). In the right panel, the merged images of phase-contrast (PC; gray) and the fluorescence signals were shown.

\section{Table 1 List of compounds that affect the proliferation of $T$. parva-infected lymphocytes.}

T. parva-infected G6TpM cells and ConA-stimulated bovine lymphocytes were cultured with $10 \mu \mathrm{M}$ each of 190 inhibitors (SCADS inhibitor kits I and II) for $24 \mathrm{~h}$, and cell proliferation rates were determined by BrdU-incorporation assay. The list shows 36 compounds that inhibited the proliferation of $T$. parva-infected lymphocytes by $>90 \%$ compared with cells mock-treated with DMSO, and had specific inhibitory effects on $T$. parva-infected lymphocytes of $<30 \%$ compared with ConA-stimulated lymphocytes, shown as TP/ConA (\%) in this table.

\section{Table2 A list of the cell lines used in this study.}

Five Theileria-infected cell lines, including cells infected with T. parva Muguga and T. parva Marikebuni, and five non-infected cell lines were used in this study. Expression of surface markers was analyzed by flow cytometry following staining with bovine monoclonal antibodies directed against CD4 (ILA-12), CD8 
(ILA-105), CD3 (MM1A), $\gamma \delta$ (GB21A), and IgM (IL-A30).

\section{References}

Bartel, F., et al., 2002. Alternative and aberrant splicing of MDM2 mRNA in human cancer. Cancer Cell. 2, 9-15.

Bartel, F., et al., 2001. Novel $m d m 2$ splice variants identified in pediatric rhabdomyosarcoma tumors and cell lines. Oncol Res. 12, 451-7.

Bode, A. M., Dong, Z., 2004. Post-translational modification of p53 in tumorigenesis. Nat Rev Cancer. 4, 793-805.

Bouska, A., et al., 2008. Mdm2 promotes genetic instability and transformation independent of p53. Mol Cell Biol. 28, 4862-74.

Brown, C. G., et al., 1973. Letter: Infection and transformation of bovine lymphoid cells in vitro by infective particles of Theileria parva. Nature. 245, 101-3.

Brown, W. C., Logan, K. S., 1986. Bovine T-cell clones infected with Theileria parva produce a factor with IL 2-like activity. Parasite Immunol. 8, 189-92.

Busuttil, V., et al., 2010. NF-אB inhibits T-cell activation-induced, p73-dependent cell death by induction of MDM2. Proc Natl Acad Sci U S A.

Cahilly-Snyder, L., et al., 1987. Molecular analysis and chromosomal mapping of amplified genes isolated from a transformed mouse $3 \mathrm{~T} 3$ cell line. Somat Cell Mol Genet. 13, 235-44.

Chang, C. J., et al., 2004. PTEN regulates Mdm2 expression through the P1 promoter. J Biol Chem. 279, 29841-8.

del Aguila, C., et al., 2006. Encephalitozoon microsporidia modulates p53-mediated apoptosis in infected cells. Int J Parasitol. 36, 869-76.

Dobbelaere, D., Heussler, V., 1999. Transformation of leukocytes by Theileria parva and T. annulata. Annu Rev Microbiol. 53, 1-42.

Dobbelaere, D. A., et al., 2000. Theileria parva: taking control of host cell proliferation and survival mechanisms. Cell Microbiol. 2, 91-9.

Dobbelaere, D. A., Kuenzi, P., 2004. The strategies of the Theileria parasite: a new twist in host-pathogen interactions. Curr Opin Immunol. 16, 524-30.

Fakharzadeh, S. S., et al., 1991. Tumorigenic potential associated with enhanced expression of a gene that is amplified in a mouse tumor cell line. EMBO J. 10, 1565-9.

Feng, J., et al., 2004. Stabilization of Mdm2 via decreased ubiquitination is mediated by protein kinase 
B/Akt-dependent phosphorylation. J Biol Chem. 279, 35510-7.

Forte, E., Luftig, M. A., 2009. MDM2-dependent inhibition of p53 is required for Epstein-Barr virus B cell growth transformation and infected cell survival. J Virol. 83, 2491-9.

Ganguli, G., Wasylyk, B., 2003. p53-independent functions of MDM2. Mol Cancer Res. 1, 1027-35.

Gottlieb, T. M., Oren, M., 1996. p53 in growth control and neoplasia. Biochim Biophys Acta. 1287, 77-102.

Gu, L., et al., 2008. MDM2 antagonist nutlin-3 is a potent inducer of apoptosis in pediatric acute lymphoblastic leukemia cells with wild-type p53 and overexpression of MDM2. Leukemia. 22, $730-9$.

Guergnon, J., et al., 2003. Apoptosis of Theileria-infected lymphocytes induced upon parasite death involves activation of caspases 9 and 3. Biochimie. 85, 771-6.

Haller, D., et al., 2010. Cytoplasmic sequestration of p53 promotes survival in leukocytes transformed by Theileria. Oncogene. 29, 3079-86

Haupt, Y., et al., 1997. Mdm2 promotes the rapid degradation of p53. Nature. 387, 296-9.

Heussler, V. T., et al., 2001a. The Akt/PKB pathway is constitutively activated in Theileria-transformed leucocytes, but does not directly control constitutive NF-kappaB activation. Cell Microbiol. 3, $537-50$.

Heussler, V. T., et al., 2001b. Inhibition of apoptosis by intracellular protozoan parasites. Int J Parasitol. 31, 1166-76.

Heussler, V. T., et al., 1999. The intracellular parasite Theileria parva protects infected T cells from apoptosis. Proc Natl Acad Sci U S A. 96, 7312-7.

Heussler, V. T., et al., 2002. Hijacking of host cell IKK signalosomes by the transforming parasite Theileria. Science. 298, 1033-6.

Honda, R., Yasuda, H., 2000. Activity of MDM2, a ubiquitin ligase, toward p53 or itself is dependent on the RING finger domain of the ligase. Oncogene. 19, 1473-6.

Hulliger, L., et al., 1964. Mode of Multiplication of Theileria in Cultures of Bovine Lymphocytic Cells. Nature. 203, 728-30.

Irvin, A. D., et al., 1975. Comparative growth of bovine lymphosarcoma cells and lymphoid cells infected with Theileria parva in athymic (nude) mice. Nature. 255, 713-4.

Ivanov, V., et al., 1989. Infection with the intracellular protozoan parasite Theileria parva induces constitutively high levels of NF-kappa B in bovine T lymphocytes. Mol Cell Biol. 9, 4677-86.

Jones, S. N., et al., 1998. Overexpression of Mdm2 in mice reveals a p53-independent role for Mdm2 in tumorigenesis. Proc Natl Acad Sci U S A. 95, 15608-12. 
Juven, T., et al., 1993. Wild type p53 can mediate sequence-specific transactivation of an internal promoter within the $m d m 2$ gene. Oncogene. 8, 3411-6.

Katzer, F., et al., 2006. Extensive genotypic diversity in a recombining population of the apicomplexan parasite Theileria parva. Infect Immun. 74, 5456-64.

Komori, H., et al., 1996. Predominant p53 mutations in enzootic bovine leukemic cell lines. Vet Immunol Immunopathol. 52, 53-63.

Kumar, S. K., et al., 2003. Design, synthesis, and evaluation of novel boronic-chalcone derivatives as antitumor agents. J Med Chem. 46, 2813-5.

Lawrence, J. A., Irvin, A. D., Theilerioses. In: J. A. W. Coetzer, et al., Eds.), Infectious Diseases of Livestock. Oxford university press, New York, 1994, pp. 307-341.

Mayo, L. D., Donner, D. B., 2001. A phosphatidylinositol 3-kinase/Akt pathway promotes translocation of Mdm2 from the cytoplasm to the nucleus. Proc Natl Acad Sci U S A. 98, 11598-603.

Momand, J., et al., 1992. The mdm-2 oncogene product forms a complex with the p53 protein and inhibits p53-mediated transactivation. Cell. 69, 1237-45.

Ogawara, Y., et al., 2002. Akt enhances Mdm2-mediated ubiquitination and degradation of p53. J Biol Chem. 277, 21843-50.

Phelps, M., et al., 2003. p53-independent activation of the hdm2-P2 promoter through multiple transcription factor response elements results in elevated hdm2 expression in estrogen receptor alpha-positive breast cancer cells. Cancer Res. 63, 2616-23.

Rocchi, M. S., et al., 2006. The kinetics of Theileria parva infection and lymphocyte transformation in vitro. Int J Parasitol. 36, 771-8.

Sasayama, T., et al., 2007. Trans-4-lodo,4'-boranyl-chalcone induces antitumor activity against malignant glioma cell lines in vitro and in vivo. J Neurooncol. 85, 123-32.

Shiels, B., et al., 2006. Alteration of host cell phenotype by Theileria annulata and Theileria parva: mining for manipulators in the parasite genomes. Int J Parasitol. 36, 9-21.

Shimizu, H., et al., 2002. The conformationally flexible S9-S10 linker region in the core domain of p53 contains a novel MDM2 binding site whose mutation increases ubiquitination of p53 in vivo. $J$ Biol Chem. 277, 28446-58.

Siddik, Z. H., 2003. Cisplatin: mode of cytotoxic action and molecular basis of resistance. Oncogene. 22, 7265-79.

Steinman, H. A., et al., 2004. An alternative splice form of Mdm2 induces p53-independent cell growth and tumorigenesis. J Biol Chem. 279, 4877-86.

Tao, W., Levine, A. J., 1999. Nucleocytoplasmic shuttling of oncoprotein Hdm2 is required for 
Hdm2-mediated degradation of p53. Proc Natl Acad Sci U S A. 96, 3077-80.

Teodoro, J. G., Branton, P. E., 1997. Regulation of apoptosis by viral gene products. J Virol. 71, 1739-46.

Tergaonkar, V., et al., 2002. p53 stabilization is decreased upon NFkappaB activation: a role for NFkappaB in acquisition of resistance to chemotherapy. Cancer Cell. 1, 493-503.

Toledo, F., Wahl, G. M., 2006. Regulating the p53 pathway: in vitro hypotheses, in vivo veritas. Nat Rev Cancer. 6, 909-23.

Veldhoen, N., et al., 1999. A novel exon within the mdm2 gene modulates translation initiation in vitro and disrupts the $\mathrm{p} 53$-binding domain of $\mathrm{mdm} 2$ protein. Oncogene. 18, 7026-33.

Vogelstein, B., et al., 2000. Surfing the p53 network. Nature. 408, 307-10.

von Schubert, C., et al., 2010. The transforming parasite Theileria co-opts host cell mitotic and central spindles to persist in continuously dividing cells. PLoS Biol. 8. e1000499.

Vousden, K. H., Lu, X., 2002. Live or let die: the cell's response to p53. Nat Rev Cancer. 2, 594-604.

Weber, J. D., et al., 1999. Nucleolar Arf sequesters Mdm2 and activates p53. Nat Cell Biol. 1, 20-6.

Wu X Fau - Bayle, J. H., et al., 1993. The p53-mdm-2 autoregulatory feedback loop. Genes Dev. 7, 1126-32.

Yaswen, P., Campisi, J., 2007. Oncogene-induced senescence pathways weave an intricate tapestry. Cell. $128,233-4$. 
A

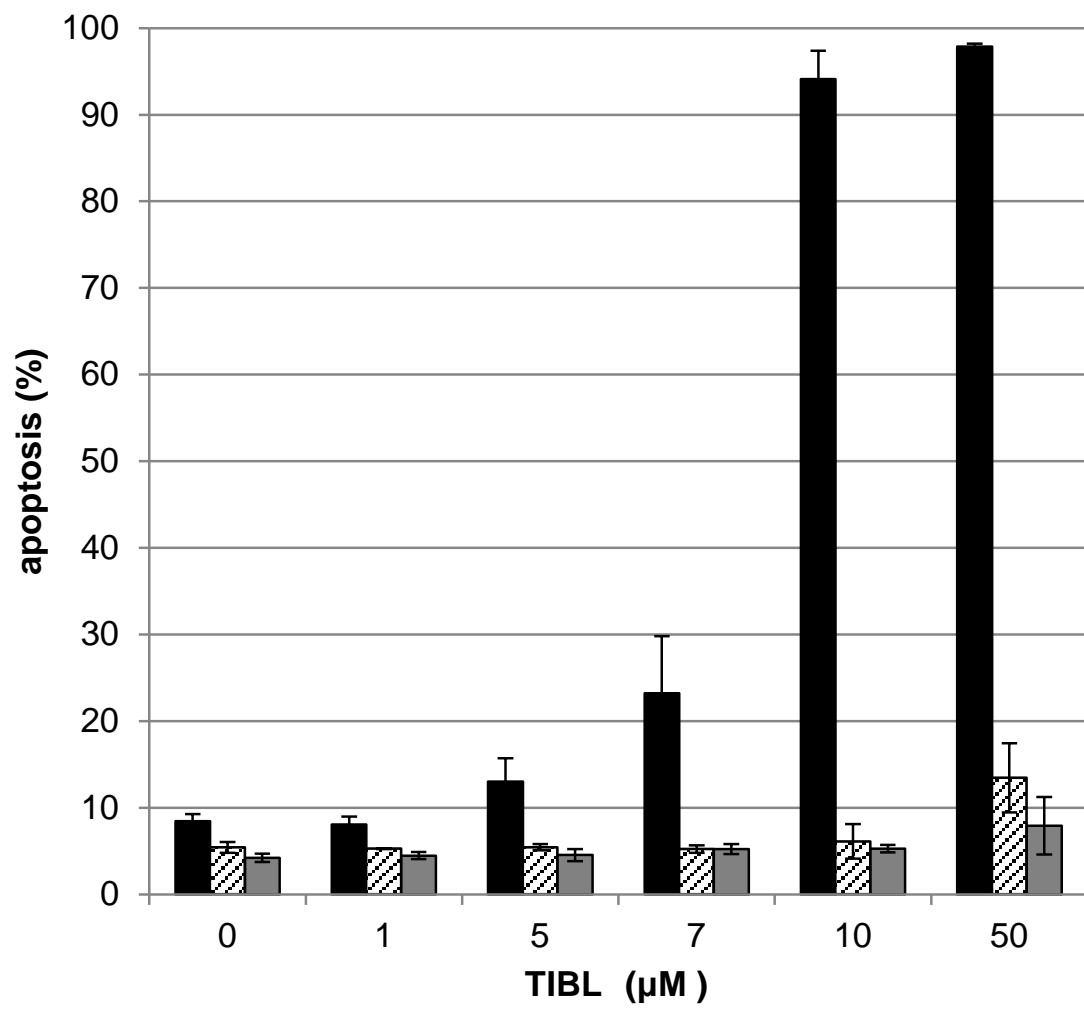

- T. parva (G6TpM) $\square$ BTL-26 $\square$ MDBK

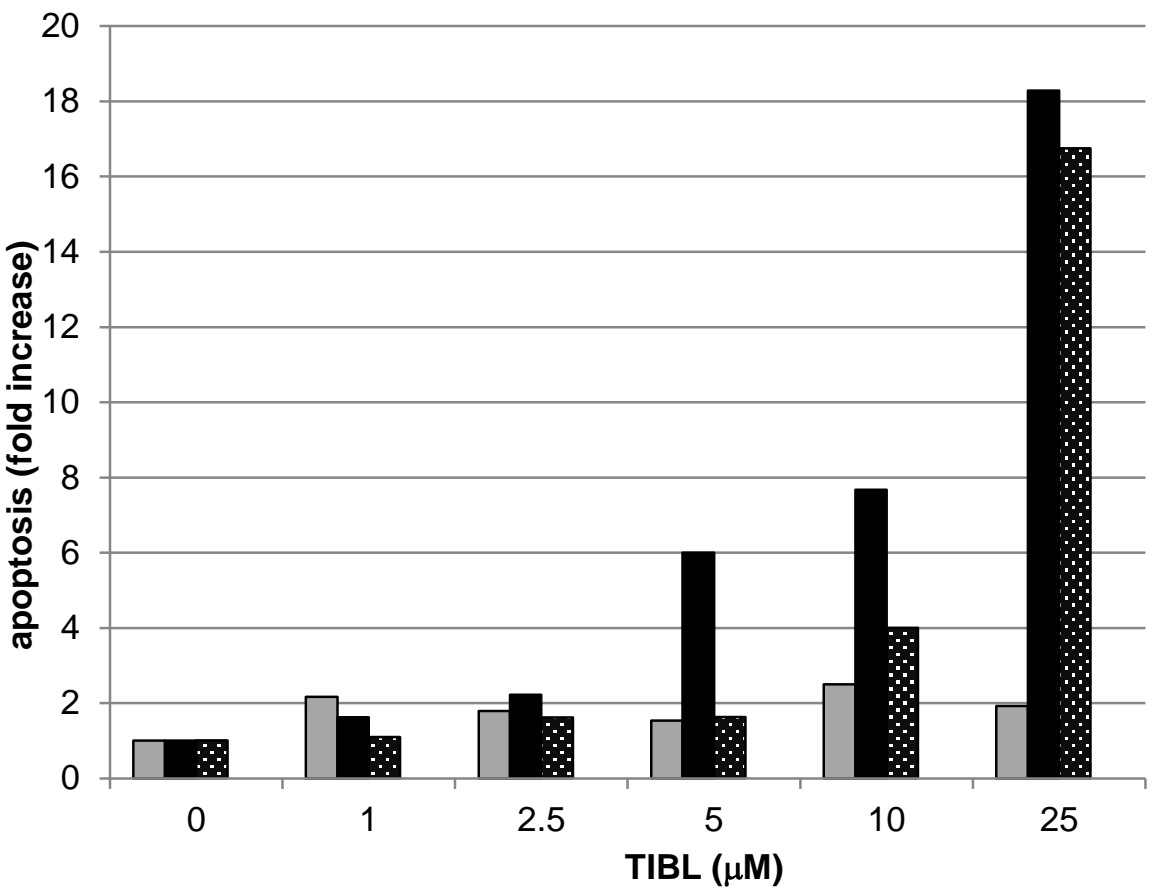

$\square$ 951ConA

๑ 951-E43TPMa 0 011TPM 


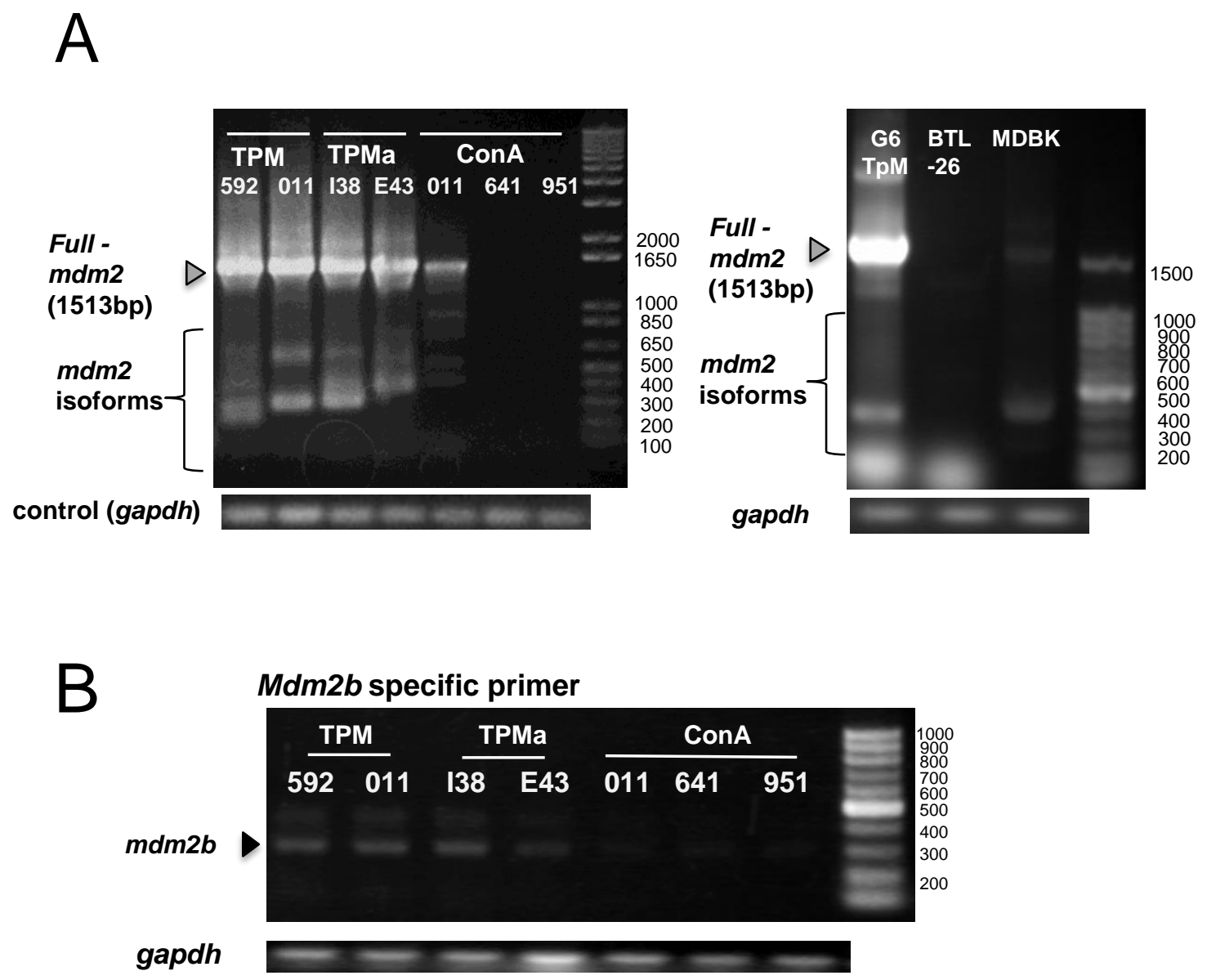


human MDM2

bovine MDM2

human MDM2alpha

MDM2-TPalpha

canine alpha domain

MDM2-TPR3U

MDM2-TPR3L

MDM2-TPFL 7

human FB28

1DM2-TP2

human

bovine MDM2

human MDM2alpha

MDM2-TPalpha

MDM2-TPR3U

MDM2-TPR3L

MDM2-TPFL7

human FB28

MDM2-TP2b

human MDM2b

human MDM2

bovine MDM2

human MDM2alpha

MDM2-TPalpha

MDM2-TPR3U

MDM2-TPR3L

MDM2-TPFL7

human FB28

MDM2-TP2b

human MDM2b

human MDM2

bovine MDM2

human MDM2alpha

human MDM2alpha

MDM2-TPalpha

MDM2-TPR3U

MDM2-TPR3L

MDM2-TPFL7

human FB28

MDM2-TP2b

human MDM2b

human MDM2

bovine MDM2

human MDM2alpha

MDM2-TPalpha

MDM2-TPR3U

MDM2-TPR3L

MDM2-TPR3L

MDM2-TPFL7

human FB28

MDM2-TP2b

human MDM2b
P53 binding domain

MCNTNMSVPTDGAVTTSQIPASEQETLVRPKPLLLKLLKSVGAQKDTYTMKE ATphā dōmāiñ ----VLFYLGQY IMTKRLYDEKQQHIVYCSNDLLGDLFGVPSF MCNTNMSVPTDGAVTTSQIPASEQETLVRPKPLLLKLLKSVGAOKDTYTMKEDFLGIPGSQVKNFCTRDT*VQVTDLSGIEVLFYLGQYIMTKRLYDEKQOHIVYCSNDLLGDLFGVPS MCNTNMSVSTDGAVSTSOIPASEQETLVRPKPLLLKLLKSVGAOKDTYTMKED-LGIHGSQVKNFCTKDT*VQYTDLSGIEVIFYLGQYIMTKRLYDEKQQHIVYCSNDLLGDLFGVPS WFLGIHGSQVKNFCTRDT*VQYTDLSGIE

MCNTNMSVSTDGAVSTSOIPASEQETLVRPKPLUKL KSVGAOKD

MCNTNMSVSTDGAVSTSOIPASEOETLVRPKPLLLKLLKSVGAOKDTYTMKE- -

-VIFYLGQY

NCNTMSVPTDGAVTTSOIPASEQETLVRPKPLLLKLLKSVGAQKDTYTMKE -

CNTNMSVSTDGAVSTSOIPASEOETL

MCNTNMSVPTDGAVTTSQIPASEQETL-

SVKEHRKIYTMIYRNLVVVNQQ-ESSDSGTSVSENRCHLEGGSDQKDLVOELQEEKPSSSHLVSRPSTSSRRRAISETEENSDELSGERQRKRHKSDSISLSFDESLALCVIREICCERS SVKEHRK IYTMIYRNLVVVSOQAEPSDSGTSVSENRCHLEGGSNOKDLVQELOEEKPSSSDMVSRPSTSSRRRAVSETEENSDELPGERQRKRHKSDNISLSFDESLALCVIREICCERS SVKEHRKIYTMIYRNLVVVNQQ-ESSDSGTSVSENRCHLEGGSDQKDLVOELQEEEKPSSSHLVSRPSTSSRRRAISETEENSDELSGERQRKRHKSDSISLSFDESLALCVIREICCERS
SVKEHRKIYTMIYRNLVVVSOQAEPSDSGTSVSENRCHLEGGSNOKDLVQELOEEKPSSSDMVSRPSTSSRRRAVSETEENSDELPGERQRKRHKSDNISLSFDESLALCVIREICCERS

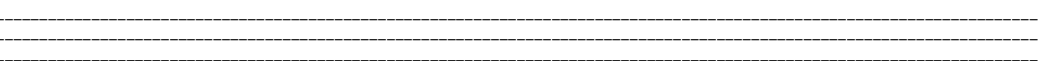

SSSESTGTPSNPDLDAGVSEHSGDWLDQDSVSDOFSVEFEVESLDSEDYSLSEEGQELSDEDDEVYQVTVYQAGESDTDSFEEDPEI SLADYWKCTSCNEMNPPLPSHCNRCWALRENWL SSSESTGTPSNPDLDAGVSEHSGDWLDQDSVSDQFSVEFEVESLDSEDYSLSEEGQELSDEDDEVYRVTVYQAGESDTDSFEEDPE I SLADYWKCTSCNEMNPPLPPHCNRCWALRENWL SSSESTGTPSNPDLDAGVSEHSGDWLDODSVSDOFSVEFEVESLDSEDYSLSEEGOEL SDEDDEVYQVTVYYAGESDTDSFEEDPE ISLADYWKCTSCNEMNPPLPSHCNRCWALRENWL SSSESTGTPSNPDLDAGVSEHSGDWLDQDSVSDOFSVEFEVESLDSEDYSLSEEGOELSDEDDEVYRVTVYQAGESDTDSFEEDPEISLADYWKCTSCNEMNPPLPPHCNRCWALRENWL

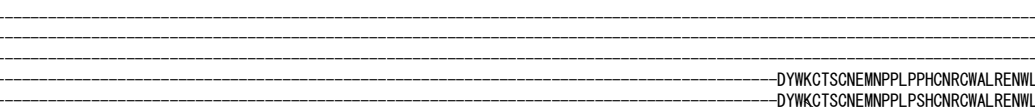

PEDKGKDKGEISEKAKLENSTQAEEGFDVPDCKKTIVNDSRESCVEENDDKI TQASQSOESEDYSOPSTSSSI IYSSQEDVKEFEREETQDKEESVESSLPLNAIEPCVI CQGRPKNGC PEDKGKDKGNMSEKAKL GDSMOEDEGFDVPDCKKSTVSDSRESCVEENDDK ITOASL SOESEDYSOPSTSNS IYYSSOEDVKEFEREETODKEESMESSFPLNAIEPCVICOGRPKNGCI PEDKGKDKGEISEKAKLNSTOAEEGEDVDCKKTIVNDSRESCVEENDDKITASOSOESEDYSOPSTSSS IYSSOEDVKEFEREETODKEESVESSLPLNAIEPCVICOGPYNGCI PEDKGKDKGIMSEKAKLGDSMEDEGDVPDCKKSTVSDSRESCYEENDDKITOASLSOESEDYSOPSTSHSUYSSOEDVKEFEREETODKEESMESSFPI A SSOEDVKEFEREETQDKEESMESSFPLNAIEPCVICQGRPKNGC PEDKGKDKGNMSEKAKLGDSMOEDEGFDVPDCKKSTVSDSRESCVEENDDKI TQASLSOESEDYSQPSTSNS I IYSSOEDVKEFEREETQDKEESMESSFPLNAIEPCVICQGRPKNGCI
PEDKGKDKGEI SEKAKLENSTQAEEGFDVPDCKKTIVNDSRESCVEENDDKI TQASQSOESEDYSOPSTSSSI IYSSOEDVKEFEREETQDKEESVESSLPLNAIEPCVICQGRPKNGCI

\section{RING finger domain}

VHGKTGHLMACFTCAKKLKKRNKPCPVCRQPIQMIVLTYFP -491 VHGKTGHLMACFTCAKKLKKRNKPCPVCROPIOMIVLTYFP -492 VHGKTGHLMACFTCAKKLKKRNKPCPVCRQPIQMIVLTYFP -520 VHGKTGHLMACFTCAKKL KKRNKPCPVCROPIOMIVLTYFP -520 VHGKTGHLMACFTCAKKL KKRNKPCPVCROPIOMIVLTYFP -119

$\begin{array}{ll}- & -58 \\ - & -67 \\ - & -67\end{array}$

VHGKTGHLMACFTCAKKL KKRNKPCPVCROPIOMIVL TYFP -218

VHGKTGHLMACFTCAKKLKKRNKPCPVCRQPIOMIVLTYFP -218

full mom2

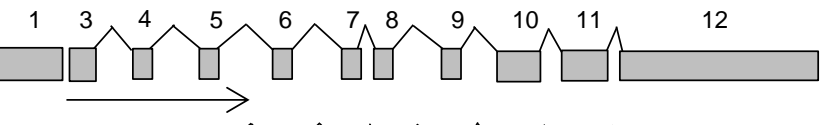

mdm2-TPalpha

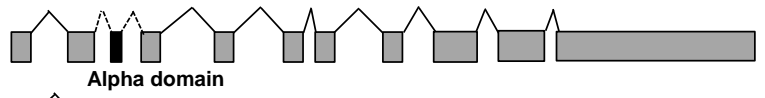

mdm2-TP R3U

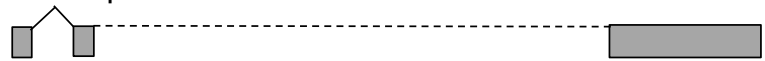

mdm2-TPR3L

mdm2-TPFL7

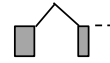

$m d m 2-T P 2 b$

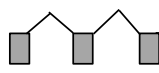


A $\frac{\text { TPM }}{592011} \frac{\text { TPMa }}{\text { I38 E43 }} \frac{\text { ConA }}{011641951}$ MDM2 (90-kDa)

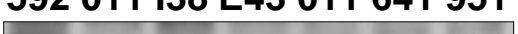

Actin

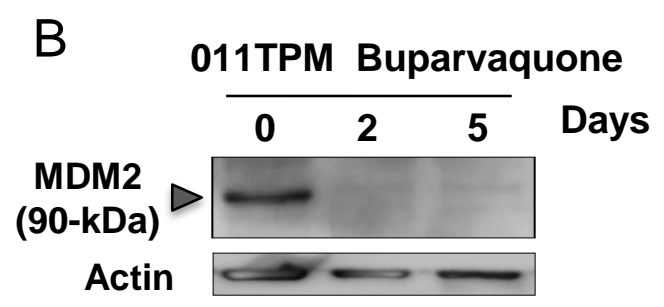

C

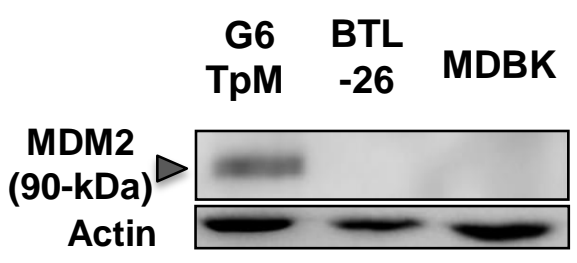

D

E
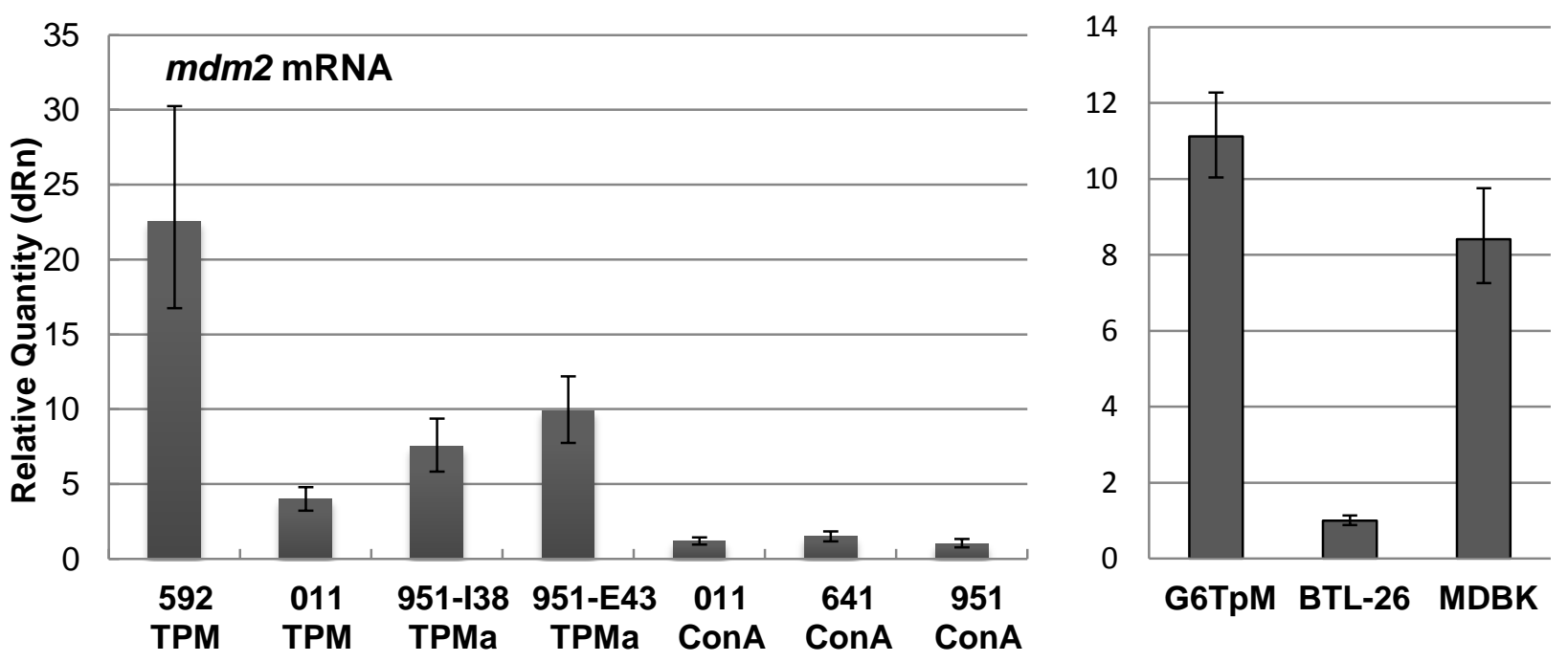

Figure 4 
A

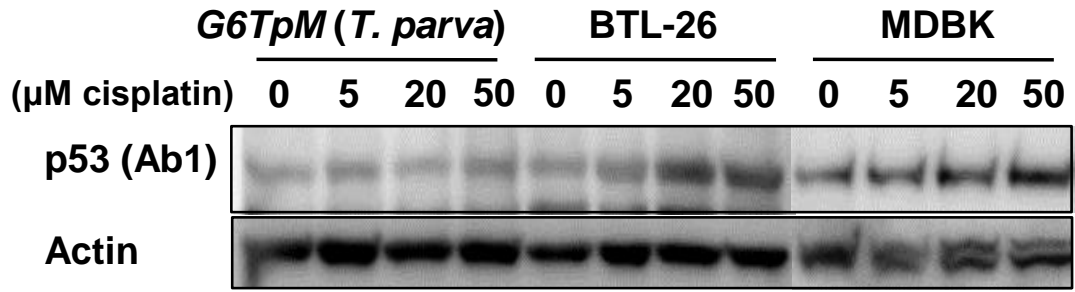

B

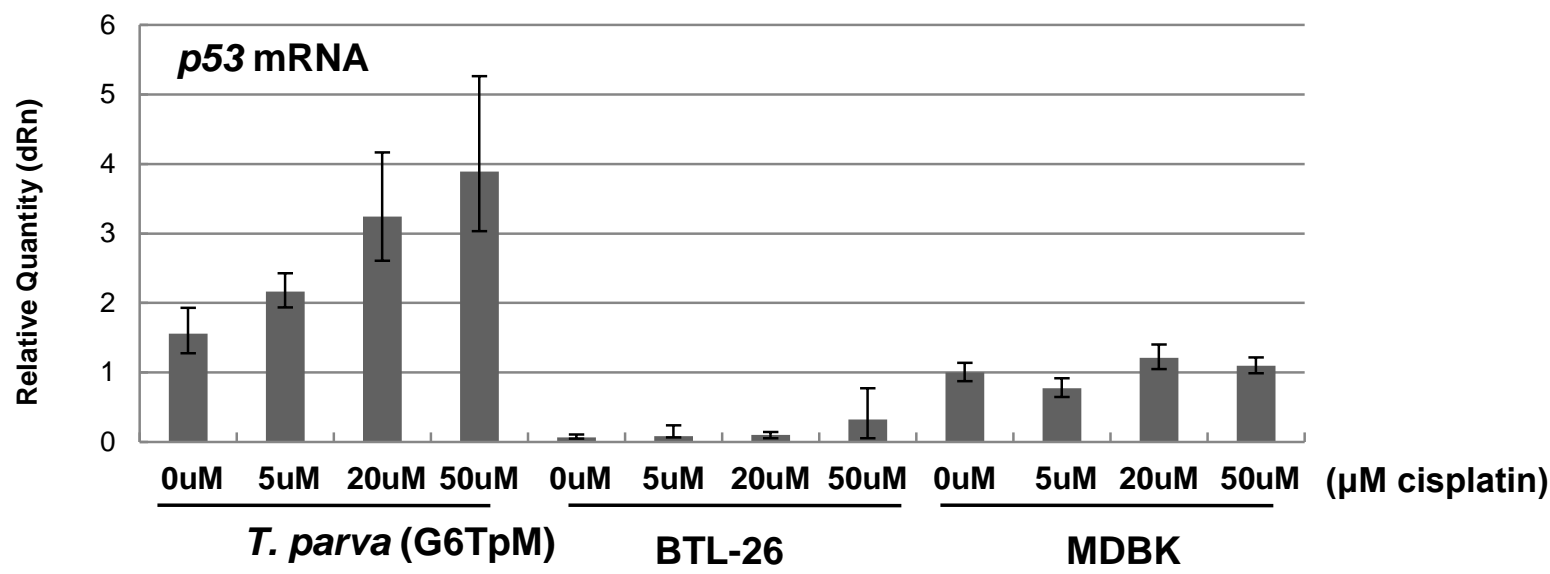

C

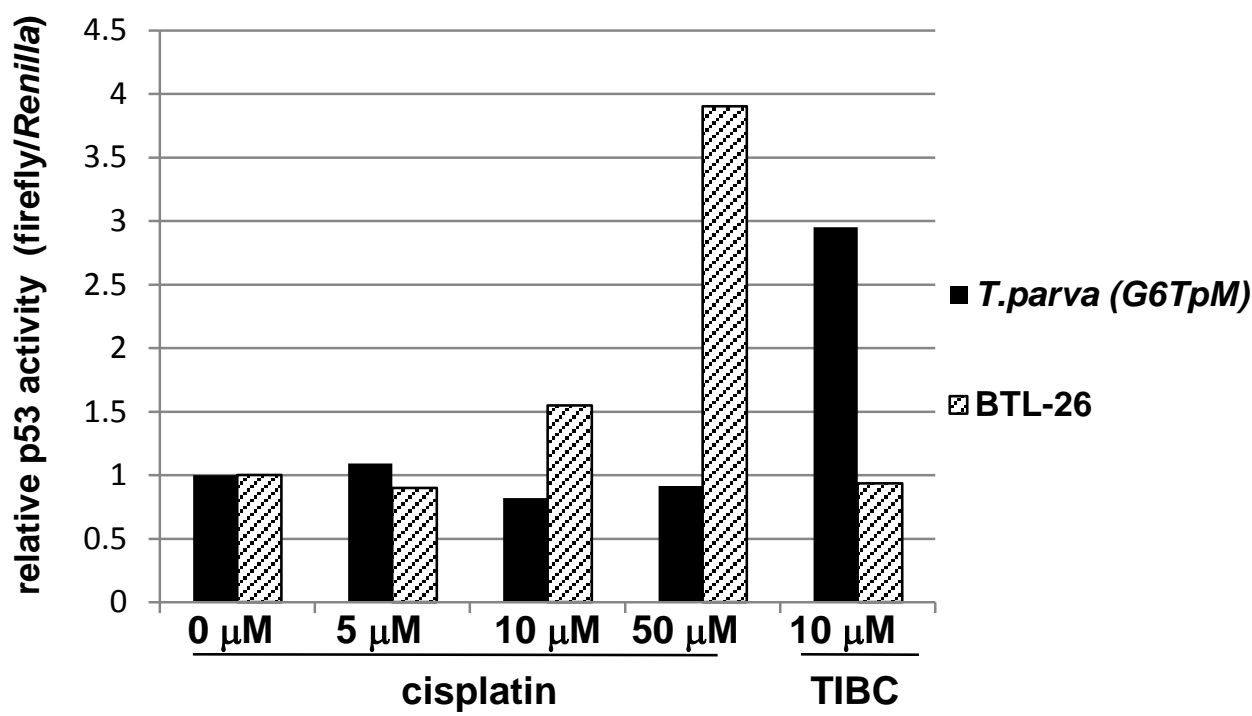

D T. parva (G6TpM)

p53

Bax Actin 

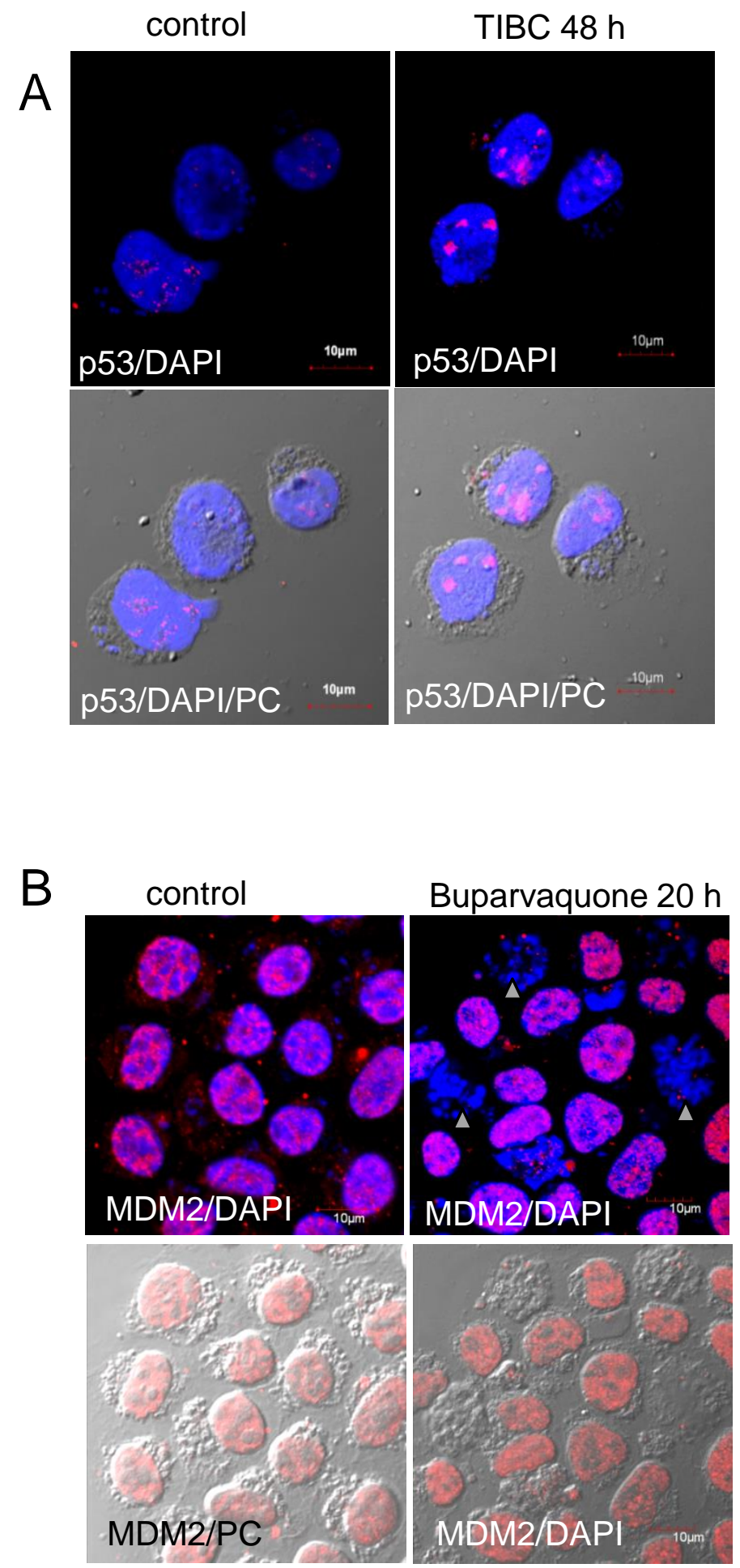
Table 1. A list of compounds that affect the proliferation of T. parva-infected lymphocytes.

\begin{tabular}{|c|c|c|c|}
\hline & categoly & inhibitor & $\mathrm{TP} / \operatorname{Con} \mathrm{A}(\%)$ \\
\hline 1 & glucosidase I, II & Deoxynojirimycin & 0.53 \\
\hline 2 & Jak-2 & Cucurbitacin I & 1.33 \\
\hline 3 & lipoxygenase & Nordihydroguaiaretic acid (NDGA) & 1.44 \\
\hline 4 & guanylate cyclase & LY 83583 & 1.59 \\
\hline 5 & MPTP opener & Lonidamine & 1.88 \\
\hline 6 & kinesin Eg5 & Monastrol & 2.36 \\
\hline 7 & guanylate cyclase & ODQ & 2.62 \\
\hline 8 & fatty acid synthase (FAS) & $\mathrm{C} 75$ & 2.93 \\
\hline 9 & HAT & Anacardic acid & 3.46 \\
\hline 10 & HIF & Chetomin & 4.17 \\
\hline 11 & HIF-1a hydroxylase & Dimethyloxalylglycine & 4.65 \\
\hline 12 & MPTP & Ro 5-4864 & 4.65 \\
\hline 13 & cathepsin B & CA-074 & 5.34 \\
\hline 14 & Bcr-Abl & AG957 & 6.60 \\
\hline 15 & farnesyltransferase & FTI-276 & 7.51 \\
\hline 16 & telomerase & b-Rubromycin & 7.56 \\
\hline 17 & HER2 (erbB2/neu), EGFR & AG825 & 9.08 \\
\hline 18 & PKG & KT 5823 & 9.70 \\
\hline 19 & DAG kinase & R59022 & 11.18 \\
\hline 20 & MDM2 & TIBC & 12.05 \\
\hline 21 & FAS & Cerulenin & 12.12 \\
\hline 22 & Ca-ATPase & Thapsigargin & 14.71 \\
\hline 23 & Ca ionophore & Ionomycin & 15.22 \\
\hline 24 & 12-lipoxygenase & Baicalein & 16.35 \\
\hline 25 & antitumor (topo I/II) & Aclarubicin & 19.35 \\
\hline 26 & $\mathrm{CDC} 2$ & Kenpaullone & 19.83 \\
\hline 27 & CRM1 & Leptomycin B $(0.1 \mathrm{mM})$ & 20.00 \\
\hline 28 & myosin light chain kinase & ML-7 & 20.67 \\
\hline 29 & $\mathrm{Na} / \mathrm{K} / \mathrm{Mg}$ ATPase & Sanguinarine & 21.05 \\
\hline 30 & EGFR & AG1478 & 21.39 \\
\hline 31 & kinesin Eg5 & $\mathrm{HR} 22 \mathrm{C} 16$ & 21.88 \\
\hline 32 & telomerase & MST-312 & 23.86 \\
\hline 33 & antitumor (DNA) & Doxorubicin, $\mathrm{HCl}$ & 25.00 \\
\hline 34 & MDM2 & Nutlin-3 & 26.52 \\
\hline 35 & cathepsin G & Z-GLF-CMK & 26.92 \\
\hline 36 & antitumor (topo II) & Etoposide (VP-16) & 28.57 \\
\hline
\end{tabular}


T. parva-infected G6TpM cells and ConA-stimulated bovine lymphocytes were cultured with $10 \mu \mathrm{M}$ each of 190 inhibitors (SCADS inhibitor kits I and II) for $24 \mathrm{~h}$, and cell proliferation rates were determined by BrdU-incorporation assay. The list shows 36 compounds that inhibited the proliferation of $T$. parva-infected lymphocytes by $>90 \%$ compared with cells mock-treated with DMSO, and had specific inhibitory effects on T. parva-infected lymphocytes of <30\% compared with ConA-stimulated lymphocytes, shown as TP/ConA (\%) in this table. 
Table2. A list of the cell lines used in this study.

\begin{tabular}{|l|l|l|}
\hline abbreviated name & $\begin{array}{l}\text { Parasite species and strain / summary of the cell } \\
\text { lines }\end{array}$ & Host cell phenotype \\
\hline G6TpM & T. parva Muguga stock & CD4-CD8+T cell \\
\hline 592TPM & T. parva Muguga stock & B cell \\
\hline 011TPM & T. parva Muguga stock & T cell \\
\hline 951-I38TPMa & T. parva Marikebuni stock & CD4-CD8+T cell \\
\hline 951-E43TPMa & T. parva Marikebuni stock & CD4+ CD8- Tcell \\
\hline BTL-26 & bovine leukemia virus infected cell line & T cell \\
\hline MDBK & Madin Darbey bovine kidney cell line & N.D. \\
\hline $\begin{array}{l}\text { 011ConA } \\
\text { 641ConA } \\
\text { 951ConA }\end{array}$ & ConA stimulated PBMCs & N.D. (uncloned) \\
\hline
\end{tabular}

Eight Theileria-infected cell lines, including cells infected with T. parva Muguga, T. parva Marikebuni, and five non-infected cell lines were used in this study. Expression of surface markers was analyzed by flow cytometry following staining with bovine monoclonal antibodies directed against CD4 (ILA-12), CD8 (ILA-105), CD3 (MM1A), $\gamma \delta$ (GB21A), and IgM (IL-A30). 